\title{
Trabalho Docente na Educação a Distância: a leitura que o professor conferencista faz sobre o seu processo de trabalho
}

\author{
Eliane do Rocio Alberti Comparin* \\ Claudia Barcelos de Moura Abreu**
}

\begin{abstract}
Resumo
Este artigo apresenta os principais resultados sobre o processo de trabalho do professor conferencista, obtidos a partir da tese de doutorado "Concepções e tendências do trabalho docente na educação a distância", desenvolvida por meio de um estudo de caso realizado em um Instituto Federal (IF) do país, entre os anos de 2011 a 2013, que analisou como se desenvolve o trabalho dos docentes mediado pelas tecnologias de informação e comunicação (TIC) no Curso Superior de Tecnologia em Gestão Pública. O objeto de investigação neste artigo é o trabalho do professor conferencista que tem formação específica ou equivalente da área da disciplina, geralmente responsável pela elaboração do material didático, pelas atividades autoinstrutivas, pelas atividades supervisionadas e pelas questões para as provas. Nesse sentido, fazem-se, neste artigo, algumas reflexões indicativas sobre o modo como se organiza e se desenvolve o trabalho do docente conferencista na modalidade de $\mathrm{EaD}$, com base em algumas produções teóricas de pesquisadores renomados na área de EaD, como: Fidalgo (2008), Cruz (2001, 2010), Moran (2002), entre outros. A pesquisa foi desenvolvida com base em informativos e documentos impressos e digitais cedidos pelo instituto, além da realização de entrevistas com a coordenação do curso e aplicação de questionários aos professores. A partir da pesquisa empírica, foi possível demonstrar as elaborações conceituais e as contradições presentes no desenvolver do trabalho docente no curso e a percepção que apresentam desse trabalho, mediado pelas TIC. Conclui-se que, apesar de o trabalho docente ser desenvolvido coletivamente, o professor conferencista é o único responsável pela seleção de conteúdos, elaboração do planejamento, da avaliação e do material didático, bem como da aula que é exibida por meio da teleconferência.

Palavras-chave: Trabalho docente; Tecnologias de informação e comunicação;
\end{abstract}

\section{Teaching Work in Distance Education: reading the lecturer teacher makes about your work process}

\begin{abstract}
This article presents the main results of the work process of teacher lecturer, obtained from the doctoral thesis "Conceptions and trends of teaching in distance education", developed through a case study on a Federal institute of the country, between the years 2011-2013, which aimed to investigate how to develop the work of teachers mediated by information and communication technologies (TIC) in the Course of Technology in Public Management. The research object in this article is the work of the lecturer teacher who has specific training or equivalent area of discipline, usually responsible for the preparation of teaching materials, the self-instructive activities, the supervised activities and the issues to the evidence. His work is developed in the IF recording studio researched. In this sense, they make up in this present article some significant reflections on how it organizes and develops the work of the lecturer teaching in the form of distance education, based on some theoretical productions by renowned researchers in the field of distance education, as: Fidalgo (2008), Cruz (2001, 2010), Moran (2002) among others. The research was conducted based on information and printed and digital documents assigned by the institute, in addition to interviews with the course coordinator. From the empirical research, we could demonstrate the conceptual elaborations and contradictions in the development of teaching the course and the perception that present this work, mediated by ICT. And conclude that, despite the teaching be development in the community base, the lecturer teacher is solely responsible for the content selection, development planning, assessment and teaching materials, as well as the class that is displayed by teleconference.

Keywords: Teachers' work; Information and communication technologies;

\section{O trabalho do professor conferencista mediado pelas TIC}

No Curso Superior de Tecnologia em Gestão Pública do IF, na modalidade a distância, o

trabalho docente é composto por um coletivo de profissionais necessários para que aconteçam não só a teleconferência, mas também a totalidade da proposta pedagógica. Os profissionais da área de docência no curso em análise são: o professor

\footnotetext{
* Endereço eletrônico: eliane.alberti@yahoo.com.br.

** Endereço eletrônico: claudiabarcelos@ufpr.br, claudia.abreu@unifesp.br
} 
autor/conferencista (responsável por elaborar o material didático e ministrar as teleconferências), o professor web (atua junto com o professor conferencista durante as teleconferências, com a função de responder aos chats e, quando necessário, participar da aula intervindo e mediando), e os professores-tutores conceituais a distância, figuras imprescindíveis para o cumprimento do trabalho docente na modalidade a distância, que envolve as práticas pedagógicas desenvolvidas por meio das TIC, os tutores orientadores e de polo. Nesse sentido, faz-se um recorte metodológico para analisar aqui o trabalho do professor conferencista, por entender que todo o processo de trabalho no curso circunscreve-se com base no andamento do seu trabalho. Dessa forma, apresentam-se a seguir brevemente a organização pedagógica e administrativa do curso, o processo de trabalho do professor conferencista com ênfase nas teleconferências, bem como os resultados encontrados a partir análise dos dados empíricos, tendo como fundamento as categorias de análise trabalho docente, formação docente e mediação pelas tecnologias.

O Curso Superior de Tecnologia em Gestão Pública, na modalidade de $\mathrm{EaD}$ do IF pesquisado, foi criado no ano de 2008, com o objetivo, por parte do Governo Federal, de estender a sua oferta para todo o país. $\mathrm{O}$ curso visa promover a qualificação profissional, em nível superior, de servidores públicos que estão em exercício na Administração Pública do Estado em que o IF está instalado.

Qualificar os profissionais que atuam em todos os níveis da Administração Pública, oferecendo elementos que irão contribuir para a formação de gestores públicos. Permitir a compreensão da complexidade e diversidade que compõem os aspectos centrais da gestão pública. Indicar ferramentas que possam intervir concretamente para a melhoria da performance do gestor público, auxiliando na busca de alternativas e soluções. Conceder a oportunidade de ampliação de conhecimentos, permitindo maior eficácia e eficiência no exercício das atividades (PROJETO POLÍTICO PEDAGÓGICO DO CURSO, 2008, p. 10).

Para tanto, os ingressos ou ingressantes devem ter concluído o Ensino Médio e passar por um processo de seleção sob a égide dos parceiros envolvidos no projeto. $\mathrm{O}$ curso, uma parceria entre o Governo do Estado, Prefeituras, Câmaras Municipais e Associação de Servidores, tem uma duração estimada de 27 meses, com uma cargahorária de 1.680 horas, sendo acrescentadas mais 60 horas para trabalho de conclusão de curso, o que totaliza 1.740 horas. Dessa carga-horária destina-se um percentual de $30 \%$ para os momentos considerados presenciais, ou seja, a apresentação de teleconferências e a realização de provas, e os outros $70 \%$ ficam sob a responsabilidade do aluno em administrá-la, por meio de estudos de forma independente, e a prática de atividades correlacionadas em seu local de trabalho. O curso é organizado de modo a atender aos alunos de várias maneiras: por meio do material didático, do site do curso e dos encontros presenciais e virtuais. Os encontros presenciais são realizados nos polos de apoio com a presença física do professor tutor na telessala e com presença virtual dos professores conferencistas e web durante a exibição das teleconferências das disciplinas.

Os encontros virtuais se dão via chats e fóruns com o professor web e o professor-tutor conceitual nos horários estabelecidos pelo curso. A sua estrutura permite ainda contatos individuais por e-mail ou telefone para atender às necessidades dos alunos. O site do curso, denominado Trilha de Aprendizagem, tem como objetivo proporcionar, tanto para os alunos quanto para os professores, a interatividade, a troca e o armazenamento de informações de cada disciplina, de forma colaborativa.

Como dito incialmente, o funcionamento do processo de trabalho docente realizado no Curso Superior de Tecnologia em Gestão Pública é composto por uma tríade de docentes que concebem o processo educativo mediado pelas tecnologias digitais, representadas pelas teleconferências exibidas via satélite e por outras mídias integradas dispostas no AVA (chat, e-mail e fórum de discussão) e pelo DDG 0800.

Esses profissionais, apesar de terem funções distintas e ao mesmo tempo imbricadas, estão diretamente relacionados com o processo de ensino e aprendizagem dos alunos, ou seja, com o exercício da docência propriamente dita e mediada pelas tecnologias digitais.

Neste projeto as atribuições do professor conferencistas, do tutor a distância $e$ presencial são bem distintas, no entanto interligadas. Cada uma delas tem um papel 
faz sobre o seu processo de trabalho

imprescindivel e para exercer suas responsabilidades dentro de todo o processo deve possuir um perfil profissional com as habilidades e competências inerentes à função (PROJETO POLÍTICO PEDAGÓGICO DO CURSO, 2011, p. 45).

Nesse entendimento, o trabalho docente se caracteriza pela mediação das TIC entre as bases teórico-científicas da educação e a sua prática docente, de modo a propiciar aos alunos (gestores públicos) uma formação profissional que implique uma contínua interpenetração entre a teoria e a prática. No entanto, para fins de análise neste artigo, examina-se o trabalho do professor conferencista.

Esse professor, considerado também como professor autor e com formação específica ou equivalente da área da disciplina, geralmente é responsável pela elaboração do material didático, pelas atividades autoinstrutivas, supervisionadas e das questões para as provas.

Os professores conferencistas são os responsáveis pela apresentação do conteúdo durante as teleaulas, bem como pelo material de aulas e elaboração das provas e atividades supervisionadas, sendo estas duas últimas também integrantes da ferramenta de avaliação de desempenho dos alunos (PROJETO POLÍTICOPEDAGÓGICO DO CURSO, 2011, p. 43).

São também suas atribuições no AVA Trilha de aprendizagem apresentar propostas de livros, links com matérias, vídeos, artigos e outros relacionados com o conteúdo da disciplina, e ministrar as teleconferências com 11 encontros, abordando uma ou mais unidades do material didático. Tendo clareza do seu papel no curso em questão, solicitou-se que todos os professores conferencistas do Curso de Tecnologia em Gestão Pública do IF, respondessem a um questionário, a fim de compreender a percepção que apresentam sobre seu trabalho no curso. Este universo é composto por 21 (vinte e um) professores responsáveis por ministrar as 21 disciplinas.

Salienta-se que, para a análise e avaliação, será computado o número de 16 (dezesseis) professores, que corresponderá a $100 \%$ da população estudada, já que os demais (5), não se dispuseram a responder ao questionário.

Dos professores que responderam, constatou-se que 5 são funcionários públicos do IF vinculados aos cursos de nível médio e convidados a lecionar no curso superior. Os demais são contratados pela empresa terceirizada que dá suporte ao instituto. Sobre a formação e o tempo de experiência com a modalidade de $\mathrm{EaD}$, verificou-se que todos os professores conferencistas que responderam ao questionário possuem experiência com a modalidade de ensino a distância e apresentam formação específica ou proximal às disciplinas em que são responsáveis pela docência no Curso Superior de Tecnologia em Gestão Pública.

Por outro lado, discutir o trabalho pedagógico e, consequentemente, o trabalho docente em qualquer instituição de ensino, pressupõe o conhecimento do projeto político pedagógico da instituição, pois, em uma concepção de gestão democrática, o documento aponta os caminhos e elementos para a organização pedagógica e administrativa em prol da transformação social. Face ao exposto, observa-se que as instituições que ofertam à modalidade de ensino a distância também têm a necessidade de construir/reformular/avaliar o seu Projeto PolíticoPedagógico, com intuito de atender aos interesses da comunidade a que servem. Nesse sentido, perguntase aos professores se conhecem o Projeto Político e Pedagógico do Curso. 14 dos professores conferencistas alegaram que sim e tiveram acesso por meio de reuniões, palestras e pela coordenação pedagógica do curso. E 2 afirmam que o desconhecem. A esse respeito, Veiga afirma que o projeto

busca um rumo, uma direção. É uma ação intencional, com um sentido explícito, com um compromisso definido coletivamente Por isso, todo projeto pedagógico da escola é, também, um projeto político por estar intimamente articulado ao compromisso sociopolítico com os interesses reais e coletivos da população majoritária. É político no sentido de compromisso com a formação do cidadão para um tipo de sociedade (...). Pedagógico, no sentido de definir as ações educativas $e$ as características necessárias às escolas de cumprirem seus propósitos e sua intencionalidade (1995, p. 13).

Seja na modalidade presencial ou a distância, é indispensável que o professor tenha conhecimento do projeto e participe da sua 
elaboração/reelaboração quando necessário. O projeto deve ser entendido como um elemento fundamental na medida em que organiza a instituição de ensino e exerce o importante papel que lhe é atribuído, ou seja, socializar os conhecimentos produzidos historicamente pela humanidade.

No que se refere à função do professor no curso, 11 professores conferencistas responderam em linhas gerais ao que compete a sua alçada: elaborar a avaliação, o material didático e os slides das teleconferências, bem como ministrá-las. Já 4 professores apontaram elaborar os slides e ministrar as teleconferências, sendo que um professor destacou que, além disso, há necessidade de acompanhar o trabalho do professor web e do tutor conceitual.

Cabe pontuar que os professores elaboram os slides, porém contam com uma equipe técnica que os adapta de acordo com o formato para a televisão.

Em relação ao livro didático, chat e fórum de discussão, os professores foram instados a opinar se estes instrumentos são dialógicos, ou seja, permitem a interação dos alunos com as atividades propostas e os professores das disciplinas do curso. 15 professores responderam que sim, são abertos ao diálogo e proporcionam a interação dos alunos com a disciplina, com o professor e com a instituição, sendo que, desses, 3 professores fazem alguns alertas.

Acredito que sim. Existem eventuais falhas que devem ser corrigidas no decorrer das aulas. Cada professor deve, à sua maneira, interagir com os alunos, alertá-los em relação às dificuldades que podem aparecer. Professor conferencista 1

Os livros estão em constante aperfeiçoamento, mas acredito que poderiam ser mais didáticos e práticos para $o$ ambiente EaD. Ainda estão numa linguagem para aulas presenciais. Precisariam ser mais dinâmicos. Com mais figuras e imagens gráficas que facilitassem $o$ aprendizado. $O$ AVA está em constante evolução, mas ainda precisa ser aperfeiçoado... Professor conferencista 2.

Permitem, mas os da área jurídica precisam ser menos atrelados à lei e mais aprofundados. Professor conferencista 3.
É preciso considerar que, na modalidade de $\mathrm{EaD}$, os recursos tecnológicos para o desenvolvimento da aprendizagem configuram-se como um conjunto de mídias (impresso, audiovisual e informático) que deve apresentar os conteúdos contextualizados e de forma dialógica, favorecendo a construção da aprendizagem autônoma do aluno. Pelos depoimentos dos docentes, esses aspectos são atendidos pelas mídias disponibilizadas pelo curso.

O curso em análise apresenta um sistema de avaliação do processo de ensino e aprendizagem dos alunos. Tal sistema é composto pelas provas, atividades autoinstrutivas e supervisionadas, além do trabalho de conclusão de curso. Segundo as atribuições dos professores conferencistas, cabe a eles elaborar os instrumentos de avaliação para os alunos do curso. Foram unânimes as respostas afirmativas quanto à elaboração desses instrumentos avaliativos pelos professores conferencistas.

$\mathrm{Na}$ pergunta aos professores conferencistas acerca do acompanhamento do processo de avaliação da aprendizagem dos alunos, 4 responderam que não conseguem exercer esse acompanhamento, e 12 responderam que sim. Destes, 6 fizeram os seguintes apontamentos:

Sim, pela leitura dos trabalhos (atividades supervisionadas) e com a orientação dos Artigos de conclusão de curso. Entretanto, não costumo olhar o resultado das provas (avaliação presencial, feita nos polos, com peso $60 \%$ ), isto é, nunca verifiquei quais teriam sido as perguntas mais difíceis ou mais fáceis. É o sistema que corrige o gabarito... Poderíamos receber talvez uma estatística por questão, mostrando a porcentagem de acertos/erros. Professor conferencista 1

Sim. Nas disciplinas que leciono procuro sempre fazer a correção das Atividades Supervisionadas. E um retorno das aulas ministradas. É uma forma de me aproximar dos alunos. Professor conferencista 2

O processo de avaliação é bidirecional. Ao mesmo tempo em que você apresenta uma avaliação ao seu aluno, você também está sendo avaliado. Erros concentrados nas respostas indicam que o assunto não foi satisfatoriamente apresentado pelo professor, gerando dúvidas quanto ao seu aprendizado. Uma nova forma de 
apresentar o conteúdo deverá ser estuda e apresentada, para que estas dúvidas não ocorram novamente. Este processo é contínuo. Professor conferencista 3

Sim, sempre me faço presente no momento da prova. Porém, não sei quais os resultados. Professor conferencista 4

Sim, elaboro as provas e atividades, faço a devolutiva das provas, acompanho os TCC e os corrijo. Professor conferencista 5

Pergunto sobre o desempenho dos alunos na disciplina que desenvolvo. Professor conferencista 6

O processo de ensinar e de aprender na $\mathrm{EaD}$ tem suas próprias dimensões e pressupõe reciprocidade entre os sujeitos. É possível notar que alguns professores conseguem acompanhar mais de perto o processo de avaliação dos alunos por meio das atividades supervisionadas e do artigo de conclusão de curso. O mesmo não acontece com as atividades autoinstrutivas, respondidas e postadas no AVA pelos alunos e com as provas realizadas presencialmente nos polos aplicadas pelos tutores, que posteriormente lançam os gabaritos no AVA para obter os resultados e repassar o rendimento para cada aluno. A fragmentação do processo de avaliação é nítida, embora apresente alguns avanços quanto ao acompanhamento realizado pelo professor conferencista e quanto à mediação realizada pelo professor web e tutor conceitual a distância pelo chat e fórum de discussão (COMPARIN, 2013, p.130).

Conhecer o papel/função que cada profissional desempenha no sistema de $\mathrm{EaD}$ é imprescindível para estimular a integração e o desenvolvimento do trabalho em conjunto. A respeito do conhecimento do papel do tutor conceitual a distância e do professor web desenvolvido no curso, as respostas foram unânimes, sendo que 7 professores destacaram algumas questões:

Conheço e considero muito importante. Professor conferencista 1

O papel do tutor e do professor web é de fundamental importância para o desenvolvimento do curso, dando agilidade e presteza quanto à interação do aluno e o curso. Professor conferencista 2.
Sim, são eles que fazem com que os alunos se mantenham no processo de aprendizagem fora dos momentos da teleaula, tiram as dúvidas, esclarecem $e$ auxiliam. Professor conferencista 3.

Sim, desempenham o papel de aproximação entre professor e o aluno. Professor conferencista 4

Sim, atuo em algumas disciplinas como tutor web. Nunca atuei como tutor presencial, mas conheci alguns e percebo que eles são fundamentais para a motivação dos alunos e diminuir a evasão. Professor conferencista 5 - grifo do autor.

Sim. O papel dele é fundamental nesta modalidade de ensino. Ele é o professor presencial. É ele quem nos representa perante os alunos. Professor conferencista 6.

Exercem o papel de mediadores e filtro entre o professor conferencista e o aluno. Professor conferencista 7

Como se vê, as devolutivas dos professores conferencistas expressam o conhecimento que têm sobre a função dos outros professores que exercem a docência, numa perspectiva de coletividade. Como essência, a colaboração pressupõe que os profissionais trabalhem em conjunto, compartilhando ideias, experiências e conhecimentos entre si.

Os registros oferecidos pelos professores da pesquisa salientam que, além do seu trabalho, outros são imprescindíveis para que o processo de ensino e aprendizagem na modalidade de $\mathrm{EaD}$ obtenha êxito: envolvimento de todos, desde equipe técnica até o tutor local; o portal sempre funcionando; acesso e repasse de informações pelo 0800; equipe de apoio para esclarecer as dúvidas dos alunos; material didático sempre entregue antes das aulas; dedicação do aluno; atendimento individual para o aluno; setores de design instrucional e de produção de vídeo que dão qualidade visual ao material; Cabe ainda, destacar as considerações de dois professores conferencistas:

O foco principal é o aluno, é ele quem aprende o professor e os demais envolvidos assim como a tecnologia são facilitadores 
do processo, acredito no sóciocontrutivismo. Além destas questões acredito no papel do tutor de ser um motivador do aluno, o AVA é um ambiente frio e a participação do tutor é significativa para romper com este distanciamento. Professor conferencista 1.

Tutor presencial - seriedade na verificação de presenças, aplicação de provas, cumprimento das atividades. Tutor web esclarecimentos sobre conteúdo, avaliações, etc. Área pedagógica acompanhamento de todas as atividades $e$ cumprimento dos objetivos do curso. Coordenação - facilitar/dar meios para cumprimento das atividades docentes. Área administrativa - dar suporte na relação professor-alunos. Professor conferencista 2.

Sobre os principais elementos para que o trabalho do professor conferencista na $\mathrm{EaD}$ aconteça com qualidade, a maioria das respostas expressa a necessidade de interação e a forte dependência, dos indivíduos envolvidos no processo, dos meios tecnológicos, seja o material didático, AVA, outros. Esta situação é percebida nos recortes abaixo:

Livro didático adequado, Portal sempre atualizado, Canal de comunicação online com os alunos, Estúdio com equipe profissional para apoio, Coordenação que esteja sempre envolvida com o curso, equipe de designer para as conferências, sempre pronta e eficaz... Professor conferencista 1.

Uma boa equipe de estúdio, e tecnologias que deixem as aulas mais interativas. Professor conferencista 2.

Interação com outros profissionais (área de vídeo, estúdio) e professores das outras disciplinas. Uma boa equipe afinada garante a aula divertida, dinâmica e de qualidade. Professor conferencista 3.

Ter todas as áreas funcionando coordenadamente. É necessário ter melhor comunicação interna. As tarefas/atividades devem ser comunicadas previamente $e$ planejadamente. Professor conferencista 4.
Material didático chegue aos alunos antes do início das aulas (preferencialmente na semana que começará as aulas); Portal funcione de modo ininterrupto e de forma adequada; bom e adequado atendimento no 0800. Professor conferencista 5.

Apoio técnico e a participação dos alunos. Professor conferencista 6.

O processo de interação deve ser forte e constante, os sistemas devem sempre estar no ar. A confiabilidade técnica é mais do que necessária. A qualidade do material didático também, professores experientes e interessados pelos alunos garantem que o aluno procure aprender. Professor conferencista 7.

Tecnologia suficiente, apoio institucional e remuneração compativel com o grau de dificuldade. Professor conferencista 8.

Essa forma de olhar a $\mathrm{EaD}$ revela a necessidade de conceber o trabalho docente de forma coletiva $\mathrm{e}$ integrada com os demais profissionais e com as TIC disponíveis para isso. É claro que essa coletividade está subordinada às condições objetivas de trabalho no modo de organizar e conduzir o ensino a distância, assim como às interferências decorrentes das políticas públicas de educação para essa modalidade de ensino.

Quanto à intenção de continuar trabalhando na modalidade de $\mathrm{EaD}$, os relatos nos questionários indicam que todos os professores consultados pretendem continuar e fazem algumas contribuições a respeito:

Achei extremamente interessante, sem contar na abrangência que a disciplina toma. Professor conferencista 1.

Sim, pois o trabalho é gratificante e atinge um grande número de alunos interessados no aprendizado. Professor conferencista 2.

Sou concursado no setor de Educação a Distância, portanto é minha atividade principal. Além disso, me sinto realizado aqui. Professor conferencista 3.

Sim. Trata-se de uma oportunidade única 

faz sobre o seu processo de trabalho

para a disseminação de conhecimento e de aprendizagem. Professor conferencista 4.

Acredito na modalidade, quando bem desenvolvida, quando há seriedade no processo como um todo. Professor conferencista 5.

Sem dúvida, pois acredito no meu trabalho e acredito na tecnologia. Não considero os alunos como pessoas limitadas, mas sim pessoas que precisam ser desafiadas. Professor conferencista 6.

Gosto muito de ministrar aulas na EAD. Identifiquei-me muito... Professor conferencista 7 .

Fui aprovado no concurso público do IFPR $e$ pretendo tomar posse. Professor conferencista 8.

Sim, pois eu não vejo distinção entre o modelo presencial e o EaD. São veículos de ensino. Professor conferencista 9.

Ao colocar em pauta essa discussão, visualizou-se a partir das respostas dos professores um sentimento de pertencimento profissional e a construção de uma identidade com essa modalidade de ensino.

Quando indagados se tinham uma capacitação/preparação para o exercício da docência no curso, 13 professores conferencistas afirmam ter tido uma capacitação inicial para o uso das tecnologias de informação e comunicação, oferecida pelo IF e apresentaram os principais conteúdos abordados nessa capacitação, como por exemplo: como usar a lousa eletrônica/quadro interativo; postura e uso das duas câmeras; movimentação e como explanar o conteúdo ao mostrar elementos no quadro; tom de voz; uso de roupas no estúdio; relação com o tempo; como iniciar e terminar a aula; a interação com os alunos e o professor web; como deixar a aula mais atraente; forma de passar a palavra ao professor web e navegação no AVA do curso. Três professores argumentaram que desconhecem essa capacitação.

Dos 13 professores que participaram da capacitação, 6 justificam que essa capacitação/formação poderia ajudar melhor se fosse ofertada mais intensamente, com o apoio da equipe de produção de conteúdo (mídia), com uma carga-horária maior do que a prevista (em torno de $1 \mathrm{~h}$ a 3 horas) e, com ênfase sobre o como desenvolver, em sua plenitude, as funções do quadro interativo. Essa abordagem esta em consonância com as proposições de Fidalgo 2008, ao indicar a permanente necessidade de oferta de formação continuada para os professores que atuam na EaD.

Em síntese, verifica-se que há por parte do IF uma preocupação em capacitar os professores de acordo com os pressupostos teóricos e metodológicos integrados as tecnologias, próprios para desenvolver um curso na modalidade a distância.

Conforme estudo realizado, a teleconferência ocupa lugar de destaque no processo de ensino e aprendizagem do Curso Superior do IF. Um outro fator que diferenciava a aula pela videoconferência de um programade $\mathrm{TV}$, era o de que havia a possibilidade de interatividade entre os participantes, emtempo real, com imagem e som simultâneos. Com isso, além de não poder escrever umscript definitivo para seu programa, dada a imprevisibilidade do que poderia vir com aplatéia (o que diferencia a videoconferência por exemplo, de uma vídeo-aula, que é umproduto fechado), o professor também tinha que contar com a necessidade de improvisoe de flexibilidade necessários para mudanças, que são comuns à aula presencial. Essasduas condições somadas davam à aula pela videoconferência um caráter híbrido,desconhecido tanto dos alunos como dos professores.

Nesse sentido, indagou-se aos professores conferencistas como percebem a sua atuação ou como se sentem na presença das câmeras/estúdio de gravação no momento da apresentação das teleconferências. Salientam-se 15 professores que responderam que se sentem à vontade e tranquilos no estúdio, com algumas ressalvas por parte de 4 desses professores, como se vê a seguir:

Sinto-me realizado. Sempre quis ser ator, e realmente, o trabalho é muito próximo! Penso nos momentos de aproximação com a câmera, nos momentos de elevar a voz, ou baixá-la, em fazer altos e baixos de forma a 'dominar' a audiência. Isso é possivel porque o conteúdo já está pronto anteriormente, já foi revisado pela produção, então só preciso me preocupar em como deixar a aula atraente. Professor Conferencista 1 
Muito à vontade. Sinto-me, verdadeiramente em sala de aula. É claro que há uma maior responsabilidade (diante da quantidade de pessoas que estão assistindo). Todavia, isso é um incentivo para estudar mais e mais e deixar as aulas mais atrativas e facilitadoras do conhecimento. Professor Conferencista 2

No início da transmissão apreensiva $e$ depois de alguns minutos mais tranquila. Professor Conferencista 3

Eu me sinto super bem, à vontade. Tenho dificuldade em trocar de câmeras no estúdio de gravação no momento da apresentação das teleconferências. Professor Conferencista 4

Para o professor Conferencista 5, sua atuação precisa melhorar; para ele "trata-se de uma situação onde o erro é de difícil correção. Quanto a presença das câmeras é uma coisa que você vai se acostumando, chega um momento em que você já não percebe a sua presença."'(Professor Conferencista 5)

Em relação a esse fato, denota-se que na $\mathrm{EaD}$ o professor necessita ter planejamento antecipado e programado de acordo com o tempo disponível referente aos conteúdos que pretendem abordar na teleconferência, justamente por ser ao vivo, e pelo fato de o instituto não editar as teleconferências que são transmitidas para as turmas em horários contrários e disponibilizadas no AVA.

Como uma inovação tecnológica, Cruz sublinha que os cursos por teleconferência se constituem

em um desafio pedagógico, técnico $e$ administrativo para as instituições envolvidas e é preciso que se invista na melhoria da qualidade do processo de ensino/aprendizagem. Sendo assim, é importante que se conheça melhor os modos de se produzir os cursos a distância por videoconferência para permitir que não apenas os grandes centros, mas as instituições de todo país possam usufruir desse conhecimento, associar-se e repartir esforços no sentido de expandir a formação universitária brasileira (2001, p. 20).

Em relação às teleconferências apresentadas pelo Curso, estas se configuram como uma de suas ferramentas de maior importância, já que a apropriação da aprendizagem pelos alunos se dá também a partir dos encontros presencias com a exibição das teleconferências, nas telessalas dos polos de apoio presencial, exibidas via satélite nas quintas-feiras pela manhã, para diversas turmas espalhadas fisicamente em diferentes regiões. Depois da exibição ao vivo da teleconferência, o IF grava a aula e disponibiliza para os tutores de polos apresentarem para as demais turmas que funcionam em outros dias e períodos. Posteriormente, disponibiliza no AVA Trilha de Aprendizagem, para que os alunos possam assistir/rever o conteúdo trabalhado pelo professor conferencista. Geralmente essas aulas ficam disponíveis até a conclusão de cada módulo, porque sobrecarregam o ambiente. $\mathrm{O}$ Projeto Político e Pedagógico do curso não menciona esse fato, mas somente que as aulas são transmitidas ao vivo, tendo em vista que uma das principais ferramentas de informação e comunicação do curso é a teleconferência. Nas palavras de Cruz, na aula por meio da teleconferência o professor:

\section{(...) (...)(precisa dominar não apenas o conteúdo, mas os meios técnicos que permitem alcançar seus objetivos pedagógicos. Mas por outro lado, na educação a distância, da mesma maneira que no ensino presencial, as concepções educacionais de cada professor $e$ da proposta pedagógica inerente ao modelo de EAD vigente em cada instituição vão se refletir em uma participação ativa (ou não)do aluno no seu processo de aprendizagem (2010, p. 280).}

Por meio da teleconferência é possível fazer a mediação pedagógica e promover a construção coletiva do conhecimento, bem como diminuir a sensação de distância entre professores e alunos. No entanto, as teleconferências, ao mesmo tempo em que permitem a interatividade, também correm os mesmos riscos do ensino na modalidade presencial, ou seja, o professor falar o tempo todo e os alunos permanecerem em silêncio, só ouvindo.

Como uma inovação tecnológica, a teleconferência tende a se desenvolver de acordo com a proposta que lhe é apresentada e a forma como é utilizada pelos sujeitos envolvidos no processo.

Sobre as teleconferências do curso, cabe 
mencionar que a transmissão é garantida e operacionalizada por uma empresa terceirizada, que controla o sistema de $\mathrm{EaD}$ de todos os cursos, inclusive os de nível médio. Essa empresa se instalou no IF via licitação e tem como responsabilidade administrar e executar todo o modelo de EaD dos cursos em andamento. Segundo o coordenador do curso, em entrevista, esse processo "é particularmente útil para o IF, na medida em que o instituto não dispõe de todo o aparato tecnológico necessário para garantir a concreticidade da proposta em EaD”.

Como contrapartida, o IF contribui financeiramente com os serviços já prestados aos alunos, por meio do repasse de verbas públicas à empresa. $\mathrm{Na}$ prática, trata-se de uma descentralização de responsabilidades estatais através de contrato firmado entre o Poder Público e ente privado, para a implantação, gestão e execução de serviços de interesse público, que nesse caso, remete-se aos cursos na modalidade de EaD.

Nota-se aqui, o fato de o IF conceder o direito a uma empresa privada, de prover serviço público, por um determinado período de tempo, gerando certa limitação por parte do instituto, identificada pela falta de capacidade para a implantação do processo de $\mathrm{EaD}$ por meio das TIC.

As aulas gravadas também comprometem de certa forma a interatividade dos alunos com o curso, pois as dúvidas dos alunos surgidas no momento da explanação do professor conferencista, que precisam ser sanadas em tempo real, ficam sem esclarecimentos, embora, em determinados dias e horários estipulados pela coordenação de curso, os alunos possam tirar as suas dúvidas por meio do chat e do fórum de discussão sob a mediação do professor-tutor conceitual a distância.

Em entrevista, o coordenador do curso pontuou que existe a intenção, por parte do IF, de, para as próximas turmas, as aulas se concentrarem em um único período do dia e serem transmitidas ao vivo para todos os polos, com o objetivo de garantir a interatividade e, consequentemente a qualidade de ensino.

Durante a apresentação das teleconferências no estúdio, ficam dois profissionais câmeras, sendo um responsável pela focalização do professor conferencista e o outro pelo professor web. Antes da exibição da teleconferência, os professores são maquiados no camarim. Pelas observações realizadas, ficou nítida a preocupação dos professores com a aparência, tanto é que todos se apresentavam muito bem vestidos e maquiados. A saber, a percepção é de que há uma preocupação, por parte dos professores, em relação à imagem que será transmitida pela televisão. Além disso, observase que o cuidado com o "figurino" usado na aula faz parte das orientações dadas durante a capacitação dos docentes para a teleconferência, com sugestões sobre o que vestir e quais acessórios usar.

Ao iniciar a teleconferência, o coordenador do curso, na maioria das vezes presente no momento da aula, dá informes gerais importantes sobre a organização do trabalho pedagógico do curso e em seguida recita uma mensagem de incentivo, motivação para os alunos.

Para averiguar como se dá o processo de mediação docente pela teleconferência, foram realizadas observações e análises com registros sistemáticos de nove disciplinas disponibilizadas no portal Trilha de Aprendizagem das vinte e uma que compõem a grade curricular curso. Assim, procurou-se analisar, além das concepções ideológicas de cada professor conferencista, também outras questões relevantes como: a linguagem, o domínio e a clareza na explanação dos conteúdos, adequação e clareza dos objetivos da aula, postura diante das câmeras, com linguagem verbal clara, fluente e objetiva e consistência argumentativa. Há um cuidado também no uso da linguagem não-verbal, do autocontrole e segurança durante as explanações dos conteúdos bem como do desenvolvimento das aulas dentro do tempo previsto.

$\mathrm{Na}$ concepção de Cruz, a teleconferência, quando usada para fins educativos, na sala de aula é

virtualizada, ao permitir que a aprendizagem ocorra numa interação de co-presença mediada entre professores $e$ alunos. Virtualizada porque a aula pela videoconferência permite que um grupo humano desterritorializado, não-presente, compartilhe um tempo comum, sincrônico, mas quase independente de um lugar geográfico: "a sincronização substitui a unidade de lugar, a interconexão, a unidade de tempo. Mas, novamente, nem por isso o virtual é imaginário. Ele produz efeitos", como diria Lévy (1996, p. 21). Um dos efeitos pode ser o de que, embora não se saiba "onde", a conversação tem lugar. A videoconferência virtualiza a sala de aula porque problematiza o papel do professor. Ao incluir a obrigatoriedade do conhecimento tecnológico como condição 
de existência da aula, amplia as exigências de atuação do professor, que precisa dominar todos os recursos e operar câmeras e microfones para que ocorra a comunicação com os alunos e, por conseqüência, a aprendizagem (2010, p. 59).

O que se verificou durante o acompanhando das aulas do curso por teleconferência é que estas possibilitam a interatividade entre os participantes, em tempo real, com transmissão de imagens e sons simultaneamente. $\mathrm{O}$ que consequentemente impõe ao professor conferencista certa flexibilidade e improvisações quando necessárias, tornando as aulas mais dinâmicas e parecidas com as aulas presencias, rompendo a ideia de programa de televisão.

Sobre a dinamicidade das aulas, pode-se observar, em oito disciplinas, que as aulas são dinâmicas e chamam a atenção do aluno devido à utilização pelos docentes de recursos como imagens, quadro esquemático, desenhos, brincadeiras, entrevistas com a comunidade e outros, para ilustrar e enriquecer os conteúdos trabalhados nas aulas de forma clara e objetiva, expressando conceitos e análises.

$\mathrm{Na}$ maioria das teleconferências, os professores do curso representam/dramatizam personagens vinculados com o conteúdo. Por exemplo, o professor conferencista e web de uma determinada disciplina se caracterizam como Descartes para dramatizar e ilustrar o período histórico que estavam comentando. Esses mesmos professores chamam constantemente a atenção dos alunos para participarem do chat e do fórum de discussão da disciplina. Ressalta-se também a ótima interação do professor conferencista com o professor web, destacando as perguntas mais relevantes sobre os conteúdos trabalhados e postadas pelos alunos, a participação de alunos, entre outras. Moran expressa bem essa ideia:

Essa comunicação direta, ao vivo, é vista como grande diferencial neste modelo pelos coordenadores deste modelo de tele-aula. Os alunos gostam de sentir o contato com o professor ao vivo, enviar-lhe perguntas, sentir-se incluídos, mesmo que esporadicamente. Os alunos gostam desse contato com o professor, de saber-se citados, ver-se representados. Há uma certa mitificação do professor, os alunos os vêem como atores de TV. Tenho observado que professores, inicialmente resistentes a esse modelo, com a prática mudam de opinião, sentem-se confortáveis, porque a tele-aula reforça e amplia o seu papel de transmissor da informação e cria essa aura de visibilidade conferida por aparecer na TV (2009, p. 288).

Outro exemplo que serve para ilustração é o fato de alguns professores convidarem outros profissionais experientes para comentarem determinados assuntos relacionados ao conteúdo que está sendo trabalhado na aula, no sentido de aproximar a teoria/prática com a vivência. Esses exemplos mostram como deixar aula mais atraente para os alunos.

Em uma teleconferência notou-se que o professor apenas ensina o conteúdo da aula, sem utilizar qualquer outro recurso para tornar a aula mais dinâmica e atraente para o aluno. A aula se apresenta um tanto monótona, com a exibição de slides dos pontos a serem explanados pelo docente, sem qualquer dinâmica de ensino. Visualiza-se nessa teleconferência apenas uma transposição do modelo de aula do presencial para a EaD.

Constatou-se em 8 teleconferências que os professores conferencistas ministram as aulas de acordo com o material didático. 6 destes, por sua vez, complementam suas explanações com base em pesquisadores e teóricos que se reportam ao assunto em pauta, assim como a partir de suas experiências profissionais.

Em 8 teleconferências analisadas, os professores conferencistas apresentam domínio de conteúdo e os expõe com clareza e objetividade, fazendo uso de recursos disponíveis para isso.

Sobre o quadro interativo, cabe ressaltar que é pouco explorado, os professores conferencistas se detêm muito tempo na explanação (verbalização) das aulas. Esse quadro poderia ser mais utilizado: destacando palavras, conceitos que queiram chamar a atenção do aluno. Durante a explicação de determinados conteúdos, lançam alguns questionamentos para os alunos e abordam os conteúdos sempre baseado em informações atuais, legislação, e outros.

Todos demonstram postura durante a aula, com linguagem verbal clara, fluente e objetiva.

Evidenciou-se em 8 teleconferências que os docentes se utilizam também da linguagem nãoverbal por meio de gestos com a mão, expressões faciais, assim como demonstram autocontrole e 
faz sobre o seu processo de trabalho

segurança durante as explanações dos conteúdos, fazendo isso com muita comunicabilidade. Movimentam-se no estúdio de acordo com o espaço previsto para a realização das aulas diante das câmeras. Porém constatou-se que 2 professores apresentaram dificuldades de se locomover no espaço previsto do estúdio, operacionalizar o quadro interativo e o tempo necessário para a mudança de posição diante das câmeras e, ao mesmo tempo, concentrar-se na explanação do conteúdo proposto e nas intervenções feitas pelo professor web.

Os demais professores se movimentavam de acordo com as limitações do espaço físico do estúdio impostas pelo uso dos equipamentos, como por exemplo as câmeras.

Em todas as teleconferências, os professores conferencistas iniciam a aula sempre fazendo uma introdução ou uma revisão da aula anterior; na sequência apresentam os conteúdos com um suporte teórico conceitual bem fundamentado e, ao término da aula, quando há tempo, observou-se que 6 professores priorizam esse tempo para realizar uma síntese integradora do que foi trabalhado na aula.

Uma das questões que merece ser destacada diz respeito à transposição didática dos conteúdos organizados e dispostos no material didático para o aluno para o formato da teleconferência, já que exige do professor algumas habilidades, como a adequação da linguagem do livro para a teleaula, a forma de expressar, gesticular, interação. No curso, observou-se que 8 professores conseguiram fazer isso com êxito, até mesmo porque alguns já haviam ministrado outras disciplinas anteriormente no formato de $\mathrm{EaD}$, além da boa dialogicidade estabelecida entre os professores e os técnicos responsáveis pela $\mathrm{EaD}$, fator também determinante para a qualidade final das teleconferências. $\mathrm{O}$ material visual produzido pelo professor em intercomunicação com os demais profissionais garantiu a qualidade das teleconferências.

A pesquisa permitiu aferir que o tempo dedicado pelos professores para o preparo dos materiais pedagógicos (slides, material didático, imagens, textos, atividades para disponibilizar no AVA, outros) e da docência (projetar sua imagem através do vídeo, atuar, dramatizar, outros) para o formato de teleconferência, a fim de transmitir os conteúdos propostos é bem maior do que se fosse ao ensino presencial.

Daí a necessidade de o professor ter algumas habilidades inerentes ao processo de trabalho na $\mathrm{EaD}$, como por exemplo: domínio de conteúdo, de linguagem, de tom de voz, de postura e posição diante das câmeras, de controle do tempo, de interação com a equipe de estúdio, de domínio do quadro interativo e dos recursos didáticos audiovisuais, de mudanças de ritmo, de improviso quando houver falhas técnicas, e outros. Portanto, há a necessidade de preparar os docentes para a utilização não só da teleconferência, mas do sistema de EaD como um todo.

No portal do curso, no item "Ampliação do conhecimento", 7 dos professores das teleconferências estudadas colocaram sugestões de livros, artigos científicos, vídeos e reportagens como embasamento teórico para os alunos.

No que se refere à concepção das teleconferências, notou-se que os docentes não são constantemente preparados para atuar na modalidade de $\mathrm{EaD}$ e suas interfaces. A vantagem desses profissionais, ao exercerem a docência no curso, é que todos já possuem pequena ou vasta experiência com a modalidade de ensino a distância, oriunda tanto da esfera pública como da privada.

O IF promove apenas uma capacitação inicial, com duração estimada em torno de 1 a 3 horas, para cada professor. Essa capacitação é ministrada por um professor especialista em educação a distância com muita experiência na área, selecionado pela instituição privada e que dá suporte operacional ao projeto $\mathrm{EaD}$ do IF, assim como capacita os professores de todos os cursos teletransmitidos do Instituto desde 2010.

Em entrevista a esse professor, quando indagado "Quais são os critérios que considera pertinente que o professor tenha, para um bom desenvolvimento da teleconferência?", ele responde:

Capacidade de comunicação com o público alvo; Visão da abrangência geográfica do curso; Espírito de equipe; Humildade para aprender e praticar um novo modelo de ensino; Capacidade de síntese; Objetividade; Disposição para praticar conceitos de melhoria contínua.

Perguntou-se também quais foram as dificuldades que detectou durante as capacitações realizadas para os professores do curso de gestão pública:

A grande dificuldade de todos os professores é vencer o temor de ser constantemente avaliado por vários públicos. Vencido este temor o professor de 
teleaula precisa desenvolver o domínio do ambiente constituído por: câmeras, tempo limitado, objetivos a cumprir e clareza na transmissão do conteúdo para alunos que pertencem a ambientes culturas diferentes entre si e diferentes em relação ao ambiente vivenciado pelo professor de aula presencial.

Em relação à teleconferência gravada e a teleconferência que ocorre em tempo real, ou seja, ao vivo, esse profissional faz o seguinte comentário:

Uma teleaula gravada permite a edição, o que melhora sua qualidade. Uma teleaula em tempo real permite a interação $e$ a melhor transmissão da emoção do professor, o que aumenta a credibilidade da aula e do professor.

Nessa capacitação, o objetivo é possibilitar ao docente a vivência em estúdio de gravação e a familiarização com as tecnologias disponíveis para o desenvolvimento da aula por meio da teleconferência. Trata-se de um treinamento voltado para a prática, ou seja, o docente ensaia no estúdio como se fosse "dar aula" de fato, num tempo estimado, seguido por intervenções e orientações pelo professor encarregado da capacitação, alertando-o para as falhas e os problemas visualizados durante a sessão experimental, bem como para as eventuais falhas surgidas durante o desenvolvimento das teleconferências de uma disciplina.

Também são abordadas questões como: postura diante das câmeras; tom de voz, movimentação no estúdio; operacionalização do quadro interativo e dos materiais audiovisuais; como iniciar e terminar uma aula por meio da teleconferência; como chamar para a exibição de uma entrevista ou imagem e outros. Apesar de ser apenas um encontro prático, essa capacitação pode ser considerada relevante e vantajosa para os docentes que participam, já que a maioria das instituições que ofertam a $\mathrm{EaD}$, segundo a literatura, tendem a desenvolver manuais/materiais escritos para os professores, como se fosse uma receita de bolo pronta a ser aplicada.

Por entender que somente o treinamento técnico e o domínio das tecnologias não são suficientes para preparar/qualificar os docentes para $o$ processo de ensino e aprendizagem via teleconferência, o IF continua dando apoio técnico e pedagógico necessário para os docentes durante o processo subsequente da produção das teleconferências, por meio do auxílio dos técnicos, tutores orientadores, coordenação, supervisão de curso e outros.

Antes do início das etapas do curso, são realizadas reuniões registradas em ata com todos os professores conferencistas, web e tutores a distância. O objetivo destas reuniões é planejar as teleconferências de maneira a transmitir o conteúdo com precisão, além de estimular o aluno a interagir não somente durante as aulas, mas também por meio dos outros canais de comunicação disponibilizados pelo AVA do IF/EaD.

$\mathrm{Na}$ visão de Cruz, a capacitação para a produção de uma teleconferência é fundamental quando se considera o professor como produtor, diretor e apresentador da aula.

Nela, o professor se depara com uma variedade de tarefas a cumprir num ambiente essencialmente artificial, cibernético, onde o contato humano se dá apenas através dos instrumentos (2001, p. 65).

O estúdio de transmissão e gravação das teleconferências é um espaço com características de um cenário, com iluminação, isolamento acústico e cor das paredes adequadas ao ambiente de TV. Possui ao fundo o quadro interativo com o logotipo do IF e uma espécie de bancada com um computador para o professor conferencista que ministra a aula em pé, controlar os comandos de trocas de slides, caso o quadro interativo apresente problema técnicos. No mesmo estúdio também é disponibilizada uma mesa com cadeira e um computador para o professor web, que permanece sentado durante a exibição da teleconferência, interagindo com o professor conferencista e fazendo as mediações necessárias do processo de ensino e aprendizagem da disciplina por meio do chat. $\mathrm{O}$ estúdio dispõe de tecnologia de qualidade, garantindo imagens apresentadas pela teleconferência nítidas e sem distorções.

Raras, mas perceptíveis a partir da amostragem das teleconferências disponibilizadas no portal do curso, foram algumas deficiências metodológicas nesse processo, dentre elas as falhas técnicas durante a transmissão, como por exemplo: áudio baixo, com ruídos, ausência de imagens por um curto período, slides das aulas que travavam, a ausência de um tradutor de linguagem de sinais, a 
fim de atingir os não-auditivos, situações que de certa maneira interferem na qualidade do processo de ensino-aprendizagem. Essa situação apresenta alguns pontos de desvantagens na aplicação da teleconferência elucidados por Cruz:

(...) a) baixa qualidade de som e imagem; b)dificuldade de adaptar a sala da videoconferência para a situação didática; c) custos relativamente altos de implementação, instalação e manutenção do equipamento no período inicial; d) custos relativamente altos de transmissão; e) desconhecimento do potencial didático do equipamento, reduzindo seu uso apenas à reprodução de palestras, com pouca interação entre os participantes (2001, p. 78).

Esses problemas interferem na qualidade das aulas na medida em que colocam o professor numa situação de improvisação. Notou-se que, quando surgia um problema técnico durante a exibição da teleconferência, alguns professores perdiam a concentração e o raciocínio do que estavam falando. No entanto, essa situação não constituía obstáculo para outros docentes, que acabavam agindo com naturalidade e espontaneidade. Isso se deve ao fato de os docentes possuírem experiência com a modalidade de $\mathrm{EaD}$.

Para garantir a condução do curso de maneira a atender às expectativas do público ao qual se destina, o curso conta ainda com o colegiado de curso formado por alunos, professores conferencistas, web e tutores a distância do curso.

Além disso, são atribuições comuns aos professores:

- Elaborar do livro didático utilizado na teleaula;

- Dominar determinadas técnicas e habilidades para tratar de forma específica os conteúdos das disciplinas;

- Orientar o aluno em seus estudos, explicando durante as teleaulas as questões relativas aos objetivos e conteúdos da disciplina;

- Destacar durante as teleaulas a importância do estudo independente, familiarizando o aluno com a metodologia e utilização do livro didático;

- Ensinar ao aluno a adquirir técnicas de estudos e métodos de aprendizagem na modalidade à distância;

- Elaborar diferentes técnicas e procedimentos de avaliação;

- $\quad$ Favorecer a possibilidade de que o aluno avalie seu próprio processo de aprendizagem;

- Elaborar dos slides utilizados na teleaulas;

- Estruturar as atividades autoinstrutivas e supervisionadas;

- $\quad$ Elaborar e corrigir as provas de sua disciplina (PROJETO POLÍTICO E PEDAGÓGICO, 2011)

Parte-se do pressuposto de que o docente a distância precisa ter a preocupação de planejar e preparar as aulas que irá ministrar, assim como a forma de processamento de informações por parte dos alunos. E uma das formas de verificar isso, é por meio da interação estabelecida entre os alunos e o professor web, professor-tutor conceitual e tutor de polo. O professor conferencista só pode ter a certeza de que suas explanações, explicações foram devidamente absorvidas pelos alunos, quando há o retorno por parte destes através das mensagens via chat, participação nos fóruns de discussão, via 0800, ferramentas que possibilitam aos alunos encaminharem suas dúvidas, concordarem ou discordarem de determinados assuntos/conteúdos abordados pelos professores nas teleconferências. Isso foi possível comprovar por meio das análises do fórum de discussão, em que a maioria das questões postadas estava relacionada a conteúdos explicados nas aulas.

A proposta de ter o professor conferencista nesse formato de EaD é bem válida, uma vez que possibilita aos alunos manter um vínculo com o professor, tendo-o como uma referência, exatamente como acontece no ensino presencial. Presenciou-se durante as observações que os recursos tecnológicos disponíveis para acessar e transmitir as informações/conhecimento por meio da teleconferência são eficazes, mas não garantem, por si sós, a concretude do processo educativo e formativo dos alunos. O domínio dos docentes do seu processo de trabalho mediatizado pelas TIC é imprescindível para esse processo, na medida em que resulta em mediações e interações com os alunos:

Para se tornar um professor comunicador, precisa desenvolver competências de uma nova linguagem midiática para adequar-se 
às características do meio televisão e ao mesmo tempo, tornar-se um produtor/usuário/mediador. Se na escola tradicional ele pode escolher "enriquecer" sua aula com a incorporação da nova lógica que a mídia traz, na educação a distância por videoconferência ele está "imerso" no meio televisivo. Professores e alunos se encontram numa relação mediatizada, virtualizada, no sentido em que não mais repartem o mesmo espaço físico $e$ sim um outro local "fantasmagórico", no dizer de Giddens (1991, p. 141). Este lugar é virtual, pois permite a interação ao mesmo tempo presencial (onde de fato estão os participantes, em suas salas audiovisuais, tácteis e olfativas) e midiática (onde a comunicação é audiovisual, no ciberespaço, ou seja, acontece na interface) (CRUZ, 2001, p. 66).

A partir da execução de todas as etapas da pesquisa, chegou-se à conclusão de que a mediação entre os docentes por meio das teleconferências do curso ocorre de acordo com os estudos que serviram de base para a pesquisa. No formato de teleconferência do curso, parte-se do princípio que o emissor em nosso caso é o professor conferencista, formado e qualificado ao exercício da função, o qual domina os conceitos a serem ministrados e possui boa verbalização.

Desta feita, a teleconferência apresenta uma estrutura na qual o professor conferencista se apresenta, ao vivo, ministrando os conteúdos junto ao professor web, que, por sua vez, responde aos questionamentos postados pelos alunos em cada aula. Em razão da preocupação em atingir um número maior de alunos, é disponibilizada no portal uma série de slides roteirizados dos conteúdos trabalhados em cada aula das disciplinas.

Pelas observações das teleconferências de nove disciplinas, percebeu-se que oito professores conseguiram transpor os conteúdos que haviam planejado ministrar para o ambiente da teleconferência, com clareza e argumentação das ideias, controle do tempo, boa mobilidade e postura diante das câmeras, diálogo constante com o professor web, uso de materiais audiovisuais. Observou-se também que, conforme o andamento das aulas por teleconferência, os professores iam se adaptando ao ambiente virtual, demonstrando segurança nesse espaço.
Essa identificação com o espaço da teleconferência, constituído por câmeras, é extremamente importante para o desenvolvimento e a qualidade das aulas. Em entrevista com o coordenador do curso, alguns professores elaboraram o material didático, mas raramente assumiram a docência por meio das teleconferências por não se sentirem seguros diante das câmeras. Alguns até chegaram a realizar a capacitação inicial; no entanto não foram selecionados para fazer as teleconferências. Pode-se inferir ainda que alguns docentes sentiram dificuldades em operacionalizar o quadro interativo, dado o insuficiente conhecimento das potencialidades deste recurso.

Outro aspecto a ser registrado foi que a interação com os alunos se dá mediante o uso do chat, o que proporcionou, para uma minoria de professores, certo sofrimento pela dificuldade de comunicação com eles, visto que se dedicavam mais a cumprir a explanação dos conteúdos propostos no planejamento de ensino, devido ao controle do tempo e ao cumprimento das aulas conforme o material didático e também a um comodismo, já que contavam com a presença do professor web para exercer essa interação via o chat.

Considerando as observações das teleconferências e os questionários respondidos pelos professores conferencistas, verificou-se que as aulas do curso por teleconferência apresentaram formalização, estrutura, rigidez, controle do tempo, ênfase na exposição do professor frente as câmeras e uso constante de materiais audiovisuais.

Em resumo, ensinar por teleconferência exige organização do trabalho pedagógico, planejamento minuncioso, incluindo o controle do tempo previsto para o início e término da aula, tendo em vista que nesse formato há pouco ou nenhum espaço para o erro, para a improvisação. Nesse sentido, a aula por teleconferência deve ser bem estruturada com materiais didáticos de apoio previamente selecionados e com boa qualidade audiovisual, o que torna a aula mais estruturada, atraente e dinâmica para os alunos.

Diante desse contexto é lícito dizer que o trabalho do professor conferencista, apesar de ser desenvolvimento na base da coletividade, é o único responsável pela seleção de conteúdos, elaboração do planejamento, dos instrumentos de avaliação, do material didático, da produção e transmissão dos conhecimentos por meio da teleconferência, outros. A interação com os demais profissionais, professor web, tutores e outros, está condicionada ao desenvolvimento do seu trabalho. Portanto, há uma 
centralidade no trabalho do professor conferencista em relação ao desenvolvimento do processo de ensino e aprendizagem no formato de $\mathrm{EaD}$ proporcionado pelo IF pesquisado.

\section{Referências}

ABREU, Claudia Barcelos de Moura; LANDINI, Sonia Regina. Trabalho docente: a dinâmica entre formação, profissionalização e proletarização na constituição da identidade. Revista Diálogo Educacional, Curitiba, Pontifícia Universidade Católica do Paraná, v. 4, n. 8, p. 1-12, jan.-abr. 2003.

AZZI, Sandra. Trabalho docente: autonomia didática e construção do saber pedagógico. In: PIMENTA, Selma Garrido (org.). Saberes pedagógicos e atividade docente. São Paulo: Cortez, 1999.

BEHAR, Patrícia A. (orgs). Modelos pedagógicos em educação a Distância. Porto Alegre: Artmed, 2009.

BRASIL. Congresso Nacional. Decreto n. 2.494, de 10 de fevereiro de 1998. Regulamenta o art. 80 da LDB (Lei n. 9.394/96). Diário Oficial da República Federativa do Brasil, Brasília (DF), 10 fev. 1998.

BRUNO, Adriana Rocha; MORAES, Maria Cândida. O enfoque da complexidade e dos aspectos afetivo-emocionais na avaliação da aprendizagem em ambiente online. In: SILVA, Marco; SANTOS, Edméa. (Org.). Avaliação da aprendizagem em educação online. São Paulo: Edições Loyola, 2006, p. 51-66.

BRZEZINSKI, Iria. Trabalho docente, tecnologias e educação. Revista Trabalho \& Educação, Goiânia, UCG, n. 1, v.17, p. 35-54, jan./abr. 2008.

CASTELLS, Manuel. A sociedade em rede. v. 1. São Paulo: Paz e Terra, 1999.

CRUZ, Dulce Márcia. A potencialidade educacional e dialógica da videoconferência na EaD. In: SILVA, Marco; PESCE, Lucila; ZUIN,
Antônio. (Org.). Educação online. Rio de Janeiro: Wak, 2010. v. 1, p. 279-308.

Mediação pedagógica e formação docente para a EaD: Comunicação, mídias e linguagens na aprendizagem em rede. In: XV ENDIPE - Encontro Nacional de Didática e Prática de Ensino Convergências e tensões no campo do Trabalho docente: Políticas e Práticas Educacionais. Belo Horizonte: Autêntica 2010, p. 333- 353.

O professor midiático: a formação docente para a educação a distância no ambiente virtual da videoconferência. Florianópolis, 2001. 197 p. Tese de Doutorado em Engenharia de Produção - Programa de Pós-Graduação em Engenharia de Produção, Universidade Federal de Santa Catarina.

COMPARIN, Eliane do Rocio Alberti. Concepções e tendências do trabalho docente na educação a distância: um estudo de caso. Curitiba, 2013. 218 p. Tese de doutorado em Educação - Programa de Pós-Graduação em Educação, Universidade Federal do Paraná.

FIDALGO, Fernando. Encontro amplia o debate sobre a educação a distância na rede privada. Jornal Extra Classe, Belo Horizonte, SINPRO, n 122, p. 6, ago. 2007.

MORAN, José Manuel. Aperfeiçoando os modelos de EaD existentes na formação de professores. Revista Educação, Porto Alegre, v. 32, n. 3, p. 286290, set./dez. 2009.

PRETI, Oresti. A formação do professor na modalidade a distância: (des)construindo metanarrativas e metáforas. Revista Brasileira Estudos Pedagógicos, Brasília, v. 82, n. 200/201/202, p. 26-39, jan./dez. 2001.

PROJETO POLÍTICO-PEDAGÓGICO do Curso Superior de Tecnologia em Gestão PúblicaModalidade EAD. Instituto Federal do Paraná, Curitiba, 2011. 56 p.

VEIGA, Ilma Passos A. Projeto político da escola: uma construção coletiva. In: (Org.) Projeto políticopedagógico da escola: uma construção possível. Campinas, SP: Papirus, 1995. 


\section{Sobre as autoras:}

Eliane do Rocio Alberti Comparin: doutoranda pelo PPGE da UFPR.

Claudia Barcelos de Moura Abreu: professora do PPGE da UFPR e da UNIFESP.

Artigo recebido em setembro de 2014.

Artigo aprovado em abril de 2015. 